\title{
Análisis de la dependencia de la acreditación institucional: Un estudio comparativo de universidades en Chile
}

Analysis of institutional accreditation dependence: A comparative study of universities in Chile

\author{
Volumen 18, Número 1 \\ Enero-Abril \\ pp. 1-30
}

Este número se publica el $1^{\circ}$ de enero de 2018

DOI: https://doi.org/10.15517/aie.v18i1.31748

\author{
Patricia Carolina Huerta-Riveros \\ Héctor Guillermo Gaete-Feres
}

Revista indizada en REDALYC, $\underline{\text { SCIELO }}$

Revista distribuida en las bases de datos:

LATINDEX, DOAJ, REDIB, IRESIE, CLASE, DIALNET, SHERPA/ROMEO, QUALIS-CAPES, MIAR

Revista registrada en los directorios:

ULRICH'S, $\underline{\text { REDIE}}, \underline{\text { RINACE}}, \underline{\text { OEI }}$ MAESTROTECA, PREAL, $\underline{\text { CLACSO }}$ 


\title{
Análisis de la dependencia de la acreditación institucional: Un estudio comparativo de universidades en Chile \\ Analysis of institutional accreditation dependence: A comparative study of universities in Chile
}

\author{
Patricia Carolina Huerta-Riveros ${ }^{1}$ \\ Héctor Guillermo Gaete-Feres ${ }^{2}$
}

\begin{abstract}
Resumen: El presente artículo tiene como objetivo analizar la dependencia organizacional de la unidad encargada del proceso de acreditación institucional en las universidades chilenas. Para ello, se realizó un análisis cuantitativo y descriptivo de las universidades chilenas acreditadas del Consejo de Rectores y de las Universidades Privadas al año 2015. Lo anterior, a partir de información obtenida de la Comisión Nacional de Acreditación, de las páginas web e información telefónica de las universidades. Los análisis estadísticos incluyeron estadísticas descriptivas, tablas de contingencias y análisis de correspondencias múltiples. Los resultados del estudio evidencian que en las universidades del Consejo de Rectores de las Universidades Chilenas (CRUCH), el $72 \%$ de las unidades encargadas de la acreditación institucional dependen de rectoría, a diferencia de las universidades privadas que representan un 58\%. Mediante la aplicación de un análisis de correspondencias múltiples comparativo entre ambos tipos de universidad, se descubre, principalmente, una asociación entre aquellas universidades cuya unidad encargada del proceso de acreditación depende de una rectoría y presenta 4 o 5 años y 3 o 4 áreas de acreditación. De igual manera, el estudio evidencia una asociación entre las universidades que obtienen 5 áreas y 6 o 7 años, sin ser relevante, en estos casos, el tipo de universidad. Por lo tanto, se concluye que la naturaleza jurídica de una institución, sea del CRUCH o privada, no se asocia necesariamente con una mejor calidad. En definitiva, los resultados permiten confirmar la hipótesis bajo estudio, es decir, no existe asociación significativa entre la dependencia organizacional y los resultados obtenidos en el proceso de acreditación.
\end{abstract}

Palabras clave: acreditación, calidad, universidad, educación superior.

Abstract: The present article has as purpose to analyze the organizational dependency of the unit responsible for the process of institutional accreditation in the chilean universities. For this purpose, a quantitative and descriptive analysis of the accredited Chilean universities, Council of Rectors of Chilean Universities and the Private Universities, to 2015. The above, based on information obtained from the National Accreditation Commission, from the web pages and telephone information from universities. Statistical analyzes included descriptive statistics, contingency tables and multiple correspondence analysis. The results of the study show that in the universities of Council of Rectors of Chilean Universities (CRUCH), 72\% of the units responsible for institutional accreditation depend on rectory, unlike private universities, which represent 58\%. Applying a comparative multiple correspondence analysis between the two types of university, an association is found among those universities whose unit responsible for accreditation process depends on a rectory, presents 4 or 5 years and 3 or 4 areas of accreditation. In addition, the study evidences an association between universities that obtain 5 areas and 6 or 7 years, without being relevant in these cases the type of university. Therefore, the study concluded that the legal nature of an institution, $\mathrm{CRUCH}$ or private, is not necessarily associated with better quality. In definitely, the results confirm the hypothesis under study, that is, there is no significant association between the organizational dependency and the results obtained in the accreditation process.

Key words: accreditation, quality, university, higher education.

1 Directora General de Planificación y Estudios de la Universidad del Bío-Bío, Chile. Dra. Dirección de Empresas, Universidad Complutense de Madrid, España. Dirección electrónica:phuerta@ubiobio.cl

2 Rector de la Universidad del Bío-Bío, Chile. Dr. Gestión y Valoración Urbana, Universidad Politécnica de Cataluña, España.Dirección electrónica: hgaete@ubiobio.cl

Artículo recibido: 3 de abril, 2017

Enviado a corrección: 25 de setiembre, 2017

Aprobado: 04 de diciembre, 2017 


\section{Introducción}

El proceso de acreditación ha cobrado gran relevancia en diversos países, según Martínez, Tobón y Sandoval (2017, p. 80) es una tendencia mundial. Como lo demuestran los estudios de Acosta (2015), Araujo (2014), del Consejo Nacional de Acreditación (CNAChile) (2014), Cuevas (2011), Llanio, Dopico y Suros (2011), Mollis (2007, 2014), Tiscornia (2009), Tünnermann (2008), Rama (2009), Velásquez, Terrazas y Ruiz (2014), Vera y De Sierra (2012). En Chile, de manera particular, la acreditación ha sido objeto de diversas investigaciones, tales como los estudios de Cancino y Schmal (2014), Espinoza y González (2012), Gairín y Martín (2011), Lemaitre, Maturana, Zenteno y Alvarado (2012), Martínez, Tobón y Romero (2017), Minte y López (2009), Ramírez y Alfaro (2013), Rodríguez, Pedraja, Araneda, González y Rodríguez (2011), Rodríguez, Fleet y Delgado (2010), Rodríguez, Fleet, Pedraja y Rodríguez (2012), Rojas y López (2016), Torres (2012), Venables y Van Gastel (2014), Zapata y Tejeda (2009), entre otros.

En este ámbito, los procesos de acreditación en Chile poseen una especial importancia en el quehacer de las universidades por ser un requerimiento fundamental para dar garantía de la calidad de las instituciones, de las carreras y de los programas que en ellas se imparten (Comisión Nacional de Acreditación de Chile (CNA-Chile), 2015).

Además, las conducciones de estos procesos requieren de una mirada holística y sistémica de la institución, pues las dimensiones abordadas, especialmente en la acreditación institucional, son múltiples y los actores que participan en ella se encuentran en todos los estamentos y niveles jerárquicos, al igual que en el medio externo. Lo anterior, se encuentra dentro de la ley № 20.129 del Sistema Nacional de Aseguramiento de la Calidad (Ministerio de Educación de Chile, 2006). En particular, esta ley plantea que la acreditación institucional consiste en el proceso de análisis de los mecanismos existentes al interior de las instituciones autónomas de educación superior, para asegurar su calidad, considerando tanto la existencia de dichos mecanismos, como su aplicación y resultados (CNA-Chile, 2015).

De esta forma, las instituciones de educación superior se someten al proceso de acreditación con la finalidad de obtener y mantener la calidad, al igual que para acceder a los fondos estatales, y por ende, al reconocimiento que este certificado le otorga en el sistema de educación superior. De hecho, la acreditación es esencial en materia de ayudas estudiantiles, ya que los estudiantes que ingresan a la educación superior podrán acceder a financiamiento estatal o a recursos que cuenten con garantía del Estado únicamente si se 
matriculan en instituciones acreditadas. En el caso de los estudios de posgrados acreditados, sus estudiantes podrán optar a fondos concursables de becas con financiamiento estatal. Sin embargo, es importante destacar que el sistema educacional chileno se encuentra en proceso de cambio, producto de la reforma de educación superior que está actualmente en discusión, en la que se plantea que el financiamiento será a la institución que cumpla ciertos requisitos y no un "voucher" para el estudiante.

Por otra parte, es importante considerar que los procesos de acreditación requieren de unidades que los coordinen y guíen durante toda su ejecución. Estas unidades son las encargadas de llevar adelante el proceso, esto de acuerdo con los lineamientos estratégicos que le entrega su jefatura directa. Por esta razón se debe analizar la dependencia organizacional o jerárquica; es decir, analizar de quién depende directamente, las unidades que llevan adelante el proceso de acreditación institucional. Con la finalidad de analizar si este aspecto influye o no en los resultados que alcanzan las universidades. Por lo anterior, surgen algunas preguntas del tipo operativo que se vuelven estratégicas en el proceso, tales como: ¿De quién debe depender la unidad encargada del proceso de acreditación institucional? y ¿Esta dependencia influye en los resultados obtenidos?

Con la finalidad de orientar algunas respuestas a estas inquietudes, el presente estudio se estructura en los siguientes apartados: En primer lugar, se presentan las bases conceptuales de la acreditación institucional y, en segundo lugar, se analiza la dependencia organizacional de la unidad encargada del proceso de acreditación institucional. Lo anterior, a través del análisis de las universidades chilenas acreditadas al año 2015. Por último, se presentan las limitaciones, conclusiones y la bibliografía utilizada.

\section{Acreditación institucional}

Actualmente, las entidades que se presentan al proceso de acreditación institucional en Chile deberán acreditarse siempre en los ámbitos de docencia de pregrado y gestión institucional. Adicionalmente, pueden optar por la acreditación en otras áreas, tales como: investigación, docencia de postgrado y vinculación con el medio, lo cual contemplando 5 áreas en total. Además, la acreditación institucional puede extenderse hasta máximo 7 años, dicha cantidad se otorga en conformidad con el nivel de cumplimiento de los criterios de evaluación y los propósitos de las instituciones. Al cabo del plazo otorgado, las instituciones pueden repetir el proceso con el fin de optar a un nuevo período de acreditación. Consecuentemente, la reacreditación se vuelve un reto para la comunidad académica y 
administrativa (Aguilar, 2016, p. 09). En definitiva, la institución encargada de certificar este proceso es la CNA-Chile, (2015) la cual es un organismo autónomo que goza de personalidad jurídica y patrimonio propio, cuya función es verificar y promover la calidad de las Universidades, Institutos Profesionales y Centros de Formación Técnica autónomos, de las carreras y programas (CNA-Chile, 2014).

De manera particular, "las políticas de aseguramiento de la calidad han logrado ocupar un lugar central en el contexto de la educación superior en Chile y en el resto del mundo" (Zapata y Tejeda, 2009, p. 194). En efecto, a nivel latinoamericano existen estudios de las universidades ante las nuevas políticas públicas (Vera y De Sierra, 2012), lo cual demuestra los cambios en el sistema educacional más allá de las fronteras, como suelen ser los análisis en educación superior. Por ejemplo, en México, Acosta (2015, p. 169) plantea que "la educación superior privada tuvo un proceso de expansión acelerado que comenzó en la década de los ochenta, y alcanzó su momento más intenso durante los años noventa". Y Araya (2014, p. 61), señala que, en Argentina, "se adoptó el esquema norteamericano, es decir, la reducción del papel del Estado en la educación superior, la expansión del sector privado, la diversificación institucional y por ende la incorporación de la dinámica del mercado". Por esta razón, Rodríguez et al (2011, p. 410) plantean que:

La demanda por educación superior se ha visto incrementada en el mundo entero y la respuesta ha sido una expansión de la oferta universitaria tanto al interior de los países como entre éstos, donde las universidades han sido afectadas por las tendencias internacionales.

Por ello, "en las últimas décadas, las universidades chilenas se han enfrentado a nuevos escenarios de masificación, diversificación y cambios económicos" (Ramírez y Alfaro, 2013, p. 32). Sin embargo, Mollis (2007, p. 73) argumenta que, "el problema no es de diversidad de ingresos universitarios y de oferta, sino la falta de planeamiento conjunto y de articulación entre el nivel secundario y el postsecundario". Además, posteriormente plantea que se requiere "reformular la trilogía de las misiones universitarias, tales como aprender para innovar, enseñar para recrear e investigar para producir ciencia, tecnología y cultura" (Mollis, 2014, p. 44).

En esta línea, Borroto y Salas (2004, p. 02) señalan que:

La meta de la universidad latinoamericana debería responder a una triple misión, como es: Hacer socialmente relevante su capacidad de creación cultural, de 
innovación científica y tecnológica y, de formación de recursos humanos; Extender, por equidad, los conocimientos generados y acumulados en la institución a sectores amplios de la sociedad y; asegurar la excelencia por el mantenimiento y la mejora de la calidad de la docencia, investigación y extensión.

De acuerdo con Anzola (2013, p. 01), estas tres últimas funciones son los elementos que constituyen una universidad de calidad. Sin embargo, según la Organización para la Cooperación y el Desarrollo Económicos (OCDE) y el Banco Mundial (2010, p. 54), "en Chile no hay una tercera misión explícita o tarea de desarrollo regional asignada a instituciones de educación superior".

En definitiva, la Acreditación Institucional en Chile es un proceso voluntario al que se someten las instituciones de Educación Superior autónomas del país, así como las carreras de pregrado, programas de postgrado y especialidades del área de la salud, con la finalidad de obtener una certificación de calidad de sus procesos internos y de sus resultados. La acreditación certifica el cumplimiento del proyecto de la institución y la existencia, aplicación y resultados de mecanismos eficaces de autorregulación y de aseguramiento de la calidad, al interior de las instituciones (Chile, 2006). Aun así, no todas las instituciones participan del proceso, más las que sí lo hacen no obtienen los mismos resultados, esto puede estar influenciado por diversas variables, como puede ser la dependencia organizacional de la unidad encargada de la acreditación institucional.

Bajo este contexto:

Si bien el Sistema de Aseguramiento de la Calidad establece un proceso de acreditación único para las distintas instituciones, cada organización debe resolver internamente cómo lleva adelante el proceso de autoevaluación, cómo hace el seguimiento de los planes de mejora y, en definitiva, cómo gestiona la acreditación institucional e incorpora mecanismos de mejoramiento continuo. (Venables y Van Gastel, 2014, p. 52)

De hecho, la cultura de mejoramiento es un esfuerzo continuo y permanente que refleja la capacidad de autoevaluar y autorregular los diferentes procesos al interior de una institución (Flórez y Yudy, 2016, p. 6).

Por lo tanto, es importante entender que la acreditación no es un fin en sí misma (Vélez, 2015, p. 7), sino, más bien, se encuentra ligada al concepto de calidad, el cual "se ha 
convertido en una preocupación fundamental en el ámbito de la educación superior en diversas latitudes" (Llanio, Dopico, Suros, 2011, p. 03). De hecho, la calidad, bajo las normas ISO, se ha planteado como "un elemento articulador de los lineamientos de la evaluación y de la acreditación (Velásquez, Terrazas y Ruiz, 2014, p. 1213)". Sin embargo, existe una dificultad para tener una definición única de calidad, debido al carácter multidimensional del concepto (Rojas y López, 2016, p. 181).

Por otra parte, "la implementación del 'Sistema Nacional de Aseguramiento de la Calidad en Chile, ha ocasionado impactos en la gestión institucional'” (Lemaitre et al., 2012, p. 21), donde, inclusive, los resultados negativos del proceso de acreditación han servido de aprendizaje a las instituciones, pues generan modelos integrales con planes de contingencia, medidas estratégicas, de soporte y asociadas al proceso de acreditación (Minte y López, 2009), al igual que ha impulsado estudios sobre planificación estratégica y sus impactos en los resultados para la acreditación (Barra y Gómez, 2014, p. 382).

Bajo este enfoque, el interés del estudio de la acreditación también ha estado en el análisis de "los propósitos, características y dimensiones de la acreditación universitaria" (Borroto y Salas, 2004, p. 1), al igual que en el análisis de las universidades privadas en el ámbito de aseguramiento de la calidad (Rodríguez et al., 2011) y en la caracterización del sistema de aseguramiento de la calidad de la educación superior en Chile (Espinoza y González, 2012). Sin embargo, se descubrió que es menor el número de estudios que analizan las unidades encargadas de la acreditación, o su dependencia organizacional.

A modo referencial, Venables y Van Gastel (2014, p. 52) analizan los modos de organización de tres universidades, y plantean que:

Para el año 2013, de las 25 universidades que componen el Consejo de Rectores de las Universidades Chilenas ( $\mathrm{CRUCH}), 20$ de ellas cuentan con direcciones superiores que llevan adelante los procesos de acreditación, mientras que el resto posee unidades, oficinas o departamentos que cumplen con esta finalidad. De estas 20 direcciones, algunas dependen de Rectoría, otras de la Vicerrectoría de planificación y otras de la Vicerrectoría Académica, lo que más allá de la diferencia en la estructura organizacional, implica funciones diversas relacionadas con la planificación estratégica, el análisis institucional, la provisión de información para la toma de decisiones, el seguimiento del plan estratégico y la orientación del proceso de autoevaluación, entre otras. 
Lo anterior, evidencia la unidad encargada del proceso de acreditación institucional y su dependencia organizacional en general, lo cual es relevante para enfrentar el proceso de acreditación institucional y sus posibles resultados. En definitiva, la esencia de la acreditación es el aseguramiento de la calidad de los procesos que permiten la formación del estudiantado de educación superior. Estos procesos no son aislados, sino que, más bien, interactúan y se relacionan por ser parte de un sistema que se encuentra en constante funcionamiento. Por ende, el llevar adelante el proceso de acreditación institucional requiere considerar los aspectos estratégicos fundamentales, al igual que los aspectos operativos que están presentes.

De hecho, Venables y Van Gastel (2014, p. 54), plantean que:

Los resultados no dependen de cómo se organizan los procesos de autoevaluación y de mejoramiento continuo en las instituciones, aunque no es posible obviar la importancia que tiene en el proceso mismo, quizás, el modo de organización de la acreditación, utilizado por cada universidad.

En definitiva, el modo de organización se puede entender como la metodología para llevar adelante el proceso, o bien, como el modelo que soporta el proceso dentro de una institución, donde este modelo debe incluir la unidad encargada del proceso de acreditación institucional y su dependencia jerárquica, la cual entrega los lineamientos estratégicos, aunque no necesariamente influya en los resultados. Lo anterior es relevante de analizar, debido a que el reciente estudio de Martínez et al (2017) señala que uno de los problemas del proceso de acreditación es la metodología y el modelo para ella. De hecho, en el caso de las universidades chilenas, existen antecedentes que han asociado los resultados de los procesos de acreditación con aspectos que evidencian mejoramiento de la gestión institucional, tales como la creación y especialización de unidades (Rojas et al, 2016, p. 182), entre otros aspectos.

Finalmente, Acosta (2015, p. 174) argumenta que es necesario realizar estudios comparativos entre los sectores públicos y privados en lo referente a los procesos de acreditación y las instancias que lo evalúan. En esta línea, Barra y Gómez (2015, p.131) realizan un estudio comparativo entre universidades estatales y no estatales, respecto de su dirección estratégica, y por esta razón, se considera relevante profundizar en este tipo de estudios. 
En concreto, en este estudio se entenderá por acreditación: “Un proceso voluntario por medio del cual una institución educativa se somete a la opinión de un organismo externo, con la intención de obtener un reconocimiento público de la calidad de su quehacer educativo" (Martínez et al, 2017, p. 73). Las instituciones pueden obtener en Chile de 1 a 7 años de acreditación, en dos o más áreas. Cuyas áreas obligatorias son gestión institucional y docencia de pregrado. El resto de las áreas tienen un carácter opcional para las instituciones.

A continuación, se detalla el concepto de cada área de acuerdo con la Comisión Nacional de Acreditación de Chile (2013). Por gestión institucional, se entenderá el conjunto de políticas y mecanismos destinados a organizar las acciones y recursos materiales, humanos y financieros de la institución en función de sus propósitos y fines declarados. Considera la organización y estructura institucional, el sistema de gobierno y la administración de recursos humanos, materiales y financieros.

Por docencia de pregrado se entenderá como el conjunto de políticas y mecanismos institucionales destinados a asegurar la calidad de la formación conducente a título, con especial énfasis en los aspectos relacionados con el diseño y aprobación de los programas ofrecidos; con su implementación y seguimiento; y con un análisis de sus resultados y los mecanismos para revisar y modificar el currículo, la organización de los programas, los métodos pedagógicos, los recursos humanos y materiales asignados a los programas o cualquier otro aspecto que afecte la calidad de la formación entregada. Donde el grado de licenciado es el que se otorga a la persona estudiante de una universidad, que ha aprobado un programa de estudios que comprenda todos los aspectos esenciales de un área del conocimiento o de una disciplina determinada (Ministerio de Educación de Chile, 2005). Por ende, la Licenciatura es un grado universitario inferior al doctorado, en donde una persona está capacitada para cumplir con una serie de tareas en un ámbito determinado, para poder así ejercer laboralmente. A diferencia del Bachillerato, el cual es un programa académico alternativo de ingreso a la universidad que otorga el grado de Bachiller a quien ha completado un ciclo inicial de estudios universitarios de dos o cuatro semestres de duración. Con el cual le habilita para proseguir los estudios conducentes a un grado académico y/o título profesional (Ministerio de Educación de Chile, 2013). Por lo tanto, el Bachillerato refleja una orgánica académica, conformada por un conjunto de talleres, laboratorios y cursos de formación básica conducente para continuar estudios y obtener grados académicos y títulos profesionales. 
En cuanto al área de postgrado, las instituciones que opten por ella deben considerar todas las actividades de postgrado que realizan. Las instituciones que impartan programas de doctorado y opten por acreditarse en el área de la docencia de postgrado deberán otorgar grados académicos de doctor en programas sistemáticos organizados de acuerdo con las normas de la Comisión Nacional de Acreditación. Además, las instituciones que impartan programas de maestría y opten por acreditarse en el área de la docencia de postgrado deberán otorgar grados académicos de magister en programas sistemáticos, organizados de acuerdo con las normas de la Comisión Nacional de Acreditación. Estos programas deben estar vigentes, tener al menos una generación de graduados y referirse a las principales líneas de desarrollo disciplinario de la institución.

El área de investigación se entenderá como las actividades sistemáticas de búsqueda de nuevo conocimiento que impactan sustantivamente en la disciplina, tema o área a la que pertenecen. Sus resultados se expresan en publicaciones o en patentes. Para optar por esta área, la institución debe desarrollar actividades sistemáticas de investigación de alto nivel en cuanto a la rigurosidad de los proyectos y a su contribución al desarrollo disciplinario o científico en diversas áreas de su quehacer, expresadas en un conjunto significativo de proyectos de investigación integrados al sistema nacional de ciencia y tecnología.

En cambio, el área de vinculación con el medio se refiere al conjunto de nexos establecidos con el medio disciplinario, artístico, tecnológico, productivo o profesional, con el fin de mejorar el desempeño de las funciones institucionales, de facilitar el desarrollo académico y profesional de los miembros de la institución y su actualización o perfeccionamiento, o de cumplir con los objetivos institucionales. Para optar por esta área, las instituciones deben contar con mecanismos sistemáticos de vinculación con el medio, que se refieren a una parte sustantiva del quehacer de la institución y que tengan un impacto significativo en su área de influencia.

Finalmente, se entenderá por dependencia organizacional a la instancia universitaria, como la rectoría, prorrectoría, vicerrectoría (entre otras), de las cuales depende jerárquicamente la unidad encargada del proceso de acreditación institucional.

Dada la argumentación anterior, se plantea la siguiente hipótesis de investigación:

Hipótesis de investigación: La dependencia organizacional de la unidad encargada de la acreditación institucional no está asociada significativamente a los resultados obtenidos en los procesos de acreditación de las universidades públicas y privadas caeteris paribus. 


\section{Metodología}

A través de una investigación cuantitativa de las universidades chilenas y mediante la información obtenida de la Comisión Nacional de Acreditación, de las páginas web e información telefónica de las universidades, se aplica un análisis de correspondencias múltiples.

Específicamente, el estudio se divide en dos partes; en la primera, se presenta un análisis de contexto de las universidades que se encuentran acreditadas según la Comisión Nacional de Acreditación a julio del año 2015. Posteriormente, se realiza un análisis de la dependencia de la acreditación institucional, cuya información fue obtenida a través de páginas web y llamadas telefónicas al $\mathrm{CHUCH}^{3}$ en julio del año 2015 y a las universidades privadas en agosto de 2015. Lo anterior, con la finalidad de observar la dependencia organizacional de la unidad encargada de coordinar el proceso de acreditación institucional.

Se aplica análisis descriptivo, tabla de contingencia y análisis de correspondencias múltiples. Se utilizan datos cuantitativos, como los años y área de acreditación, los cuales posteriormente se transforman en variables categóricas para el estudio. Al igual que la creación de otra variable categórica, como es la dependencia organizacional de la unidad encargada del proceso de acreditación institucional. En concreto, el análisis de correspondencias múltiples es una técnica descriptiva que se utiliza para representar gráficamente la frecuencia de aparición de dos o más variables cualitativas. Para el análisis de la información, se utilizó un nivel de significancia de un 5\% y el programa estadístico SPSS 21.

\subsection{Población y objeto de estudio}

La población objeto de estudio la componen; por un lado, las 25 universidades pertenecientes al $\mathrm{CRUCH}$ y acreditadas según la CNA, cuyo periodo de análisis fue el mes de julio del año 2015 (Tabla 1). Por otro lado, está compuesta por las 19 universidades privadas acreditadas según la CNA, cuyo periodo de análisis fue el mes de agosto del año 2015.

3 Nota: $\mathrm{CRUCH}$ es el Consejo de Rectores de Universidades Chilenas, el cual está integrado por las 16 universidades públicas y 9 universidades privadas con aportes del Estado, estas últimas son: Pontificia Universidad Católica de Chile, Pontificia Universidad Católica de Valparaíso, Universidad Austral de Chile, Universidad Católica de la Santísima Concepción, Universidad Católica del Norte, Universidad de Concepción, Universidad técnica Federico Santa María, Universidad Católica de Temuco y Universidad Católica del Maule. 
Tabla 1. Número de universidades chilenas por categoría al año 2015

\begin{tabular}{|l|r|r|r|r|r|r|}
\hline $\begin{array}{c}\text { Categoría } \\
\text { universidades }\end{array}$ & \multicolumn{1}{|c|}{$\begin{array}{c}\text { Total } \\
\text { universidades }\end{array}$} & $\begin{array}{c}\text { Universidades } \\
\text { acreditadas }\end{array}$ & $\begin{array}{c}\text { Total } \\
\text { revisadas }\end{array}$ & $\begin{array}{c}\text { Total con } \\
\text { antecedentes }\end{array}$ & $\begin{array}{c}\text { Representación } \\
\text { respecto a las } \\
\text { acreditadas }\end{array}$ & $\begin{array}{c}\text { Representación } \\
\text { respecto al total }\end{array}$ \\
\hline $\begin{array}{l}\text { Consejo de } \\
\text { Rectores }\end{array}$ & 25 & 25 & 25 & 25 & $100 \%$ & $100 \%$ \\
\hline $\begin{array}{l}\text { Privadas } \\
\text { (Autónomas) }\end{array}$ & 32 & 19 & 19 & 19 & $100 \%$ & $59 \%$ \\
\hline
\end{tabular}

Fuente: Elaboración propia (2015), con información de la CNA y Consejo Nacional de Educación (CNED)

\subsection{Variables}

A continuación se presentan las variables del estudio. La dependencia organizacional se refiere a la instancia universitaria de la cual depende la unidad encargada de llevar adelante el proceso de acreditación institucional, es una variable categórica que toma el valor "1" cuando la unidad encargada de la acreditación institucional depende directamente de Rectoría; toma el valor "2" cuando depende de la Prorrectoría; el valor "3" cuando depende de la Vicerrectoría y toma el valor 4 cuando depende de una dirección.

Por otra parte, los resultados del proceso de acreditación se midieron a través de los años y áreas de acreditación institucional vigentes, otorgados por la Comisión Nacional de Acreditación (CNA) de Chile. Los años de acreditación es una variable cuantitativa que evidencia el número de años de acreditación otorgados por la CNA a la institución. Para el estudio, esta variable fue categorizada. Específicamente, para la tabla de contingencia se dividió en dos categorías: la institución posee 5, 6 o 7 años de acreditación y la institución posee 4 o menos años de acreditación. En cambio, para el análisis de correspondencias múltiples, la variable años de acreditación se categorizó de la siguiente manera: la institución posee de 1 a 3 años de acreditación, la institución posee 4 o 5 años de acreditación y la institución posee 6 o 7 años de acreditación institucional.

Finalmente, la variable áreas de acreditación institucional se refiere al número de áreas que una universidad obtiene al someterse al proceso de acreditación institucional. Como el número mínimo de áreas acreditadas son dos, esta variable cuantitativa va de 2 a 5 áreas de acreditación institucional. Variable que se categorizó con un valor de "2" cuando la universidad tiene 2 áreas acreditadas, toma el valor "3" cuando presenta 3 áreas acreditadas, toma el valor " 4 " cuando posee 4 áreas acreditadas y toma el valor " 5 " cuando obtiene 5 áreas de acreditación.

Por último, se creó la variable tipo de universidades, tomando el valor "1" cuando la universidad es del CRUCH y el valor "2" cuando la universidad es privada. Esta variable fue utilizada para el análisis comparativo. 


\section{Resultados y su análisis}

A continuación, se presenta el estado de situación de la acreditación institucional de las Universidades del CRUCH y privadas en Chile.

Tabla 2. Áreas y años de acreditación de las universidades chilenas, en promedio y porcentaje al año 2015

\begin{tabular}{|c|c|c|c|c|}
\hline Aspecto & $\begin{array}{l}\text { Universidades } \\
\text { Públicas } \\
\text { (16 } \\
\text { Universidades) }\end{array}$ & $\begin{array}{c}\text { Universidades } \\
\text { Privadas con } \\
\text { Aporte }^{4} \\
\text { (9 Universidades) }\end{array}$ & $\begin{array}{c}\text { CRUCH } \\
(25 \\
\text { Universidades })\end{array}$ & $\begin{array}{c}\text { Privadas } \\
(\mathbf{3 0} \\
\text { Universidades })\end{array}$ \\
\hline Universidades acreditadas & $100 \%(16 / 16)$ & $100 \%(9 / 9)$ & $100 \%(25 / 25)$ & $63,33 \%(19 / 30)$ \\
\hline Promedio de años acreditados & 4,44 & 5,33 & 4,76 & 4,05 \\
\hline Promedio de áreas acreditadas & 3,69 & 4,33 & 3,92 & 2,84 \\
\hline Promedio de años en Investigación & 5,25 & 5,57 & 5,4 & 4,75 \\
\hline Porcentaje de años en Investigación & $50 \%(8 / 16)$ & $77,8 \%(7 / 9)$ & $60 \%(15 / 25)$ & $13,33 \%(4 / 30)$ \\
\hline Promedio de años en Postgrado & 5,75 & 6,00 & 5,9 & 5,33 \\
\hline Porcentaje de años en Postgrado & $25 \%(4 / 16)$ & $66,7 \%(6 / 9)$ & $40 \%(10 / 25)$ & $10 \%(3 / 30)$ \\
\hline $\begin{array}{l}\text { Promedio de años en Vinculación } \\
\text { con el Medio }\end{array}$ & 4,47 & 5,5 & 4,8 & 5 \\
\hline $\begin{array}{l}\text { Porcentaje de años en Vinculación } \\
\text { con el Medio }\end{array}$ & $93,8 \%(15 / 16)$ & $88,9 \%(8 / 9)$ & $92 \%(23 / 25)$ & $30 \%(9 / 30)$ \\
\hline
\end{tabular}

Fuente: Elaboración propia (2015), a partir de www.cnachile.cl

Como se puede apreciar en la Tabla 2, al momento del estudio, el $100 \%$ de las universidades del $\mathrm{CRUCH}$ se encuentran acreditadas y su promedio de años y áreas de acreditación es superior en relación con las universidades privadas.

A continuación, la Figura 1 presenta el porcentaje de universidades acreditadas en Chile, en función del número de áreas que obtienen en la acreditación institucional, por categoría de universidad al año 2015.

4 Nota: Universidades Particulares con Aporte del Estado: Son universidades privadas creadas antes de 1980 o derivan de ellas. Actualmente son 9. Fuente: Ministerio de Educación, 29 de julio 2015. http://www.mifuturo.cl/index.php/donde-y-que-estudiar/universidades 
Figura 1. Porcentaje de universidades acreditadas en Chile, por número de áreas y categoría de universidad al año 2015

\section{- 2 áreas \\ - 3 áreas \\ - 4 áreas \\ - 5 áreas}

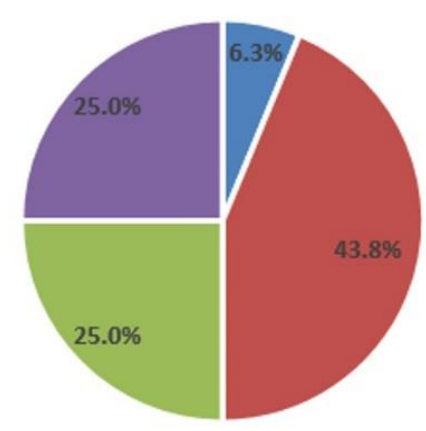

PÚBLICAS

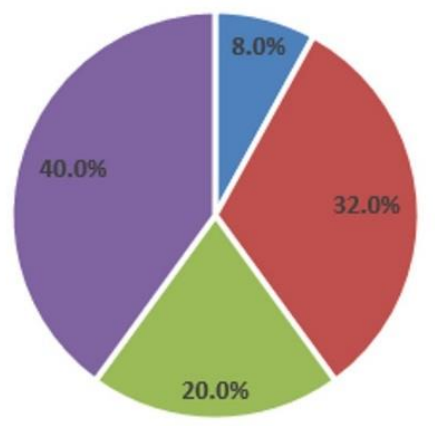

CRUCH

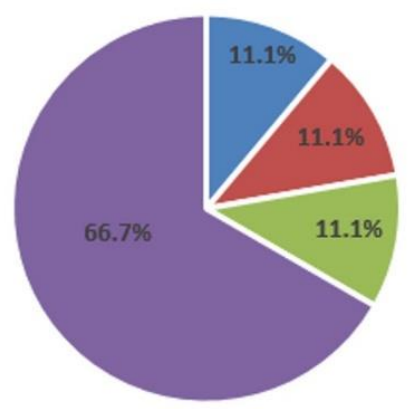

PRIVADAS CON APORTE

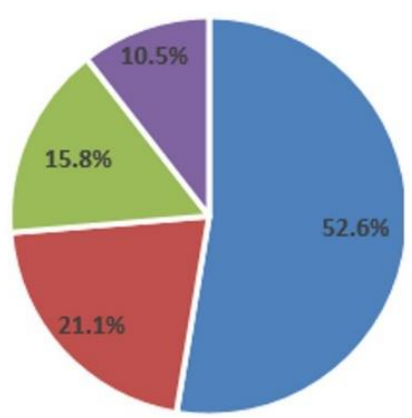

PRIVADAS

Fuente: Elaboración propia (2015), a partir de www.cnachile.cl

Como se puede apreciar en la Tabla 3, las universidades del $\mathrm{CRUCH}$ presentan un mínimo de 3 y un máximo de 7 años de acreditación, y el número de áreas acreditadas fluctúa entre 2 y 5 , a diferencia de las universidades privadas cuyo mínimo de años es de 2 , y poseen un máximo de 6 años de acreditación. No existe en el momento del estudio una universidad privada con el máximo de años de acreditación. 
Tabla 3. Estadísticos descriptivos de los años y áreas de acreditación de las universidades chilenas por categoría al año 2015

\begin{tabular}{|c|c|c|c|c|c|c|c|c|c|c|}
\hline \multirow[b]{2}{*}{ Variables del Estudio } & \multicolumn{5}{|c|}{ CRUCH } & \multicolumn{5}{|c|}{ PRIVADAS } \\
\hline & $\mathbf{N}$ & Mínimo & Máximo & Media & $\begin{array}{l}\text { Desv. } \\
\text { Típ. }\end{array}$ & $\mathbf{N}$ & Mínimo & Máximo & Media & $\begin{array}{l}\text { Desv. } \\
\text { Típ. }\end{array}$ \\
\hline $\begin{array}{l}\text { Áreas de Acreditación } \\
\text { Institucional }\end{array}$ & 25 & 2 & 5 & 3,92 & 1,03 & 19 & 2 & 5 & 2,89 & 1,05 \\
\hline $\begin{array}{l}\text { Años de Acreditación } \\
\text { Institucional }\end{array}$ & 25 & 3 & 7 & 4,76 & 1,24 & 19 & 2 & 6 & 4,11 & 1,05 \\
\hline
\end{tabular}

Fuente: Elaboración propia (2015)

La Tabla 4 presenta el porcentaje de unidades encargadas del proceso de acreditación institucional en el $\mathrm{CRUCH}$ en función de su dependencia. Dicha Tabla también agrupa el porcentaje por dependencia en general, específicamente, agrupa las diferentes vicerrectorías, como se aprecia en la columna "porcentaje acumulado por dependencia directa agrupada", en la cual se contemplan las 25 universidades. Es importante considerar que el número de unidades encargadas de la acreditación institucional y el número de universidades es el mismo. Como se puede apreciar, el $72 \%$ de las unidades que coordinan el proceso de acreditación institucional dependen directamente de una Rectoría, seguido del $20 \%$ que dependen de una Vicerrectoría y solo el $8 \%$ depende de la Prorrectoría.

Tabla 4. Porcentaje de unidades encargadas de la acreditación institucional en las 25 universidades del CRUCH en función de su dependencia al año 2015

\begin{tabular}{|c|c|c|c|c|c|c|c|}
\hline $\begin{array}{l}\text { Dependencia } \\
\text { Directa }\end{array}$ & $\begin{array}{c}\text { Unidad } \\
\text { encargada de la } \\
\text { Acreditación } \\
\text { Institucional(Al) }\end{array}$ & $\begin{array}{c}\mathrm{N}^{\circ} \text { de } \\
\text { unidades }\end{array}$ & $\begin{array}{c}\text { Porcentaje } \\
\text { de unidades } \\
\text { encargadas } \\
\text { de la Al }\end{array}$ & $\begin{array}{l}\text { Porcentaje } \\
\text { acumulado en } \\
\text { función de la } \\
\text { Dependencia } \\
\text { Directa }\end{array}$ & $\begin{array}{l}\text { Porcentaje } \\
\text { acumulado } \\
\text { por } \\
\text { Dependencia } \\
\text { Directa } \\
\text { Agrupada } \\
\end{array}$ & $\begin{array}{c}\text { Años } \\
\text { promedio }\end{array}$ & $\begin{array}{c}\text { Áreas } \\
\text { promedio }\end{array}$ \\
\hline \multirow{3}{*}{ Rectoría } & Dirección & 16 & $64 \%$ & \multirow{3}{*}{$72 \%$} & \multirow{3}{*}{$72 \%$} & \multirow{3}{*}{4,5} & \multirow{3}{*}{3,7} \\
\hline & Oficina & 1 & $4 \%$ & & & & \\
\hline & Departamento & 1 & $4 \%$ & & & & \\
\hline Prorrectoría & Dirección & 2 & $8 \%$ & $8 \%$ & $8 \%$ & 5,5 & 4,0 \\
\hline \multirow{3}{*}{$\begin{array}{l}\text { Vicerrectoría } \\
\text { Académica }\end{array}$} & Dirección & 1 & $4 \%$ & \multirow{3}{*}{$12 \%$} & \multirow{5}{*}{$20 \%$} & \multirow{5}{*}{5,4} & \multirow{5}{*}{4,6} \\
\hline & Oficina & 1 & $4 \%$ & & & & \\
\hline & Unidad & 1 & $4 \%$ & & & & \\
\hline $\begin{array}{l}\text { Vicerrectoría } \\
\text { de Desarrollo }\end{array}$ & Dirección & 1 & $4 \%$ & $4 \%$ & & & \\
\hline \begin{tabular}{l|} 
Vicerrectoría \\
de \\
Planificación y \\
Desarrollo
\end{tabular} & Dirección & 1 & $4 \%$ & $4 \%$ & & & \\
\hline \multicolumn{2}{|c|}{ Total } & 25 & $100 \%$ & $100 \%$ & $100 \%$ & & \\
\hline
\end{tabular}

Fuente: Elaboración propia (2015)

A diferencia de las universidades privadas en las cuales, de acuerdo con la Tabla 5, el $58 \%$ de las unidades que coordinan el proceso de acreditación institucional dependen 
directamente de una Rectoría, seguido del 32\% que dependen de una Vicerrectoría, el 5,2\% depende de la Prorrectoría y el 5,2\% también depende de una Dirección de Planificación y Desarrollo. Sin embargo, también se registra la existencia de una unidad a cargo del proceso que depende de una dirección.

Tabla 5. Porcentaje de unidades encargadas de la acreditación institucional en las 19 universidades privadas en función de su dependencia al año 2015

\begin{tabular}{|c|c|c|c|c|c|c|c|}
\hline $\begin{array}{l}\text { Dependencia } \\
\text { Directa }\end{array}$ & $\begin{array}{c}\text { Unidad } \\
\text { encargada } \\
\text { de la } \\
\text { Acreditación } \\
\text { Institucional } \\
\text { (Al) } \\
\end{array}$ & $\begin{array}{c}\mathrm{N}^{\circ} \text { de } \\
\text { unidades }\end{array}$ & $\begin{array}{c}\text { Porcentaje } \\
\text { de } \\
\text { unidades } \\
\text { encargadas } \\
\text { de la Al }\end{array}$ & $\begin{array}{l}\text { Porcentaje } \\
\text { acumulado en } \\
\text { función de la } \\
\text { Dependencia } \\
\text { Directa }\end{array}$ & $\begin{array}{c}\text { Porcentaje } \\
\text { acumulado } \\
\text { por } \\
\text { Dependencia } \\
\text { Directa } \\
\text { Agrupada } \\
\end{array}$ & $\begin{array}{c}\text { Años } \\
\text { promedio }\end{array}$ & $\begin{array}{c}\text { Áreas } \\
\text { promedio }\end{array}$ \\
\hline \multirow{2}{*}{ Rectoría } & Vicerrectoría & 4 & $21 \%$ & \multirow{2}{*}{$58 \%$} & \multirow{2}{*}{$58 \%$} & \multirow{2}{*}{3,8} & \multirow{2}{*}{2,5} \\
\hline & Dirección & 7 & $37 \%$ & & & & \\
\hline Prorrectoría & Dirección & 1 & $5,2 \%$ & $5,2 \%$ & $5,2 \%$ & 5 & 5 \\
\hline $\begin{array}{l}\text { Vicerrectoría } \\
\text { Académica }\end{array}$ & Dirección & 1 & $5,2 \%$ & $5,2 \%$ & \multirow{6}{*}{$32 \%$} & \multirow{6}{*}{4,3} & \multirow{6}{*}{2,8} \\
\hline $\begin{array}{l}\text { Vicerrectoría } \\
\text { de Postgrado } \\
\text { e Investigación }\end{array}$ & Dirección & 1 & $5,2 \%$ & $5,2 \%$ & & & \\
\hline $\begin{array}{l}\text { Vicerrectoría } \\
\text { de } \\
\text { Planificación y } \\
\text { Desarrollo }\end{array}$ & Dirección & 1 & $5,2 \%$ & $5,2 \%$ & & & \\
\hline $\begin{array}{l}\text { Vicerrectoría } \\
\text { de } \\
\text { aseguramiento } \\
\text { de la calidad y } \\
\text { análisis } \\
\text { institucional }\end{array}$ & Vicerrectoría & 1 & $5,2 \%$ & $5,2 \%$ & & & \\
\hline $\begin{array}{l}\text { Vicerrectoría } \\
\text { de } \\
\text { Acreditación y } \\
\text { Evaluación de } \\
\text { la calidad }\end{array}$ & Vicerrectoría & 1 & $5,2 \%$ & $5,2 \%$ & & & \\
\hline $\begin{array}{l}\text { Vicerrectoría } \\
\text { de Desarrollo } \\
\text { Institucional }\end{array}$ & Dirección & 1 & $5,2 \%$ & $5,2 \%$ & & & \\
\hline $\begin{array}{l}\text { Dirección de } \\
\text { Planificación y } \\
\text { Desarrollo }\end{array}$ & $\begin{array}{l}\text { Subdirección } \\
\text { de } \\
\text { Acreditación }\end{array}$ & 1 & $5,2 \%$ & $5,2 \%$ & $5,2 \%$ & 5 & 5 \\
\hline \multicolumn{2}{|l|}{ Total } & 19 & $100 \%$ & $100 \%$ & $100 \%$ & & \\
\hline
\end{tabular}

Fuente: Elaboración propia (2015), con información de la CNA

En la Tabla 6 se observa el porcentaje de funciones adicionales que realiza la unidad encargada de la acreditación institucional en las universidades del CRUCH y universidades privadas. En concreto, las unidades que se encargan de los procesos de acreditación institucional también abordan otras funciones, tales como el monitoreo del plan de desarrollo y de mejoramiento, en un 64\%, seguido del proceso de acreditación de carreras de pregrado en un $40 \%$ y de postgrado en un $28 \%$, entre otras funciones. Porcentajes superados en las universidades privadas con un $68 \%$ en el monitoreo del plan de desarrollo y de 
mejoramiento, en un 79\%, seguido del proceso de acreditación de carreras de pregrado en un $58 \%$ de postgrado.

Tabla 6. Porcentaje, por categoría, de funciones adicionales que realizan las unidades encargadas de la acreditación institucional en las universidades chilenas al año 2015

\begin{tabular}{|c|r|r|r|r|r|r|r|r|r|r|r|r|}
\hline \multirow{2}{*}{ Unidad } & \multicolumn{5}{|c|}{ CRUCH (25 universidades) } & \multicolumn{4}{|c|}{ Privadas (19 universidades) } \\
\cline { 2 - 11 } & MP & Pre & Pos & AIN & Pr & RSU & MP & Pre & Pos & AIN & Pr & RSU \\
\hline $\begin{array}{c}\text { Unidad } \\
\text { encargada de } \\
\begin{array}{c}\text { Acreditación } \\
\text { Institucional }\end{array}\end{array}$ & 64 & 40 & 28 & 16 & 20 & 8 & 68 & 79 & 58 & 53 & 21 & 5 \\
Nota = MP: Monitoreo del Plan; Pre: Carreras de Pregrado; Pos: Carreras de Postgrado; AIN: Análisis Institucional; Pr: Proyectos; RSU: \\
Responsabilidad Social Universitaria.
\end{tabular}

Fuente: Elaboración propia (2015)

\subsection{Tabla de contingencia}

En esta sección se utilizan pruebas estadísticas de independencia para analizar el nivel de asociación entre las variables. En concreto, en primer lugar, la dependencia organizacional de la unidad encargada de la acreditación institucional y los años de acreditación obtenidos por las Universidades del $\mathrm{CRUCH}$ y las universidades privadas y, en segundo lugar, la dependencia organizacional y el número de áreas obtenidos en la acreditación.

La Tabla 7 presenta la tabla de contingencia del número de universidades chilenas al 2015 por categoría de años de acreditación y dependencia de la unidad encargada de la acreditación institucional. Para determinar si el número de años de acreditación está asociado con la dependencia organizacional de la unidad encargada de la acreditación institucional, se realizó una prueba Chi-cuadrado de independencia y la Prueba exacta de Fisher. Se realizaron las pruebas sin considerar la universidad privada en donde la unidad encargada de la acreditación depende de una dirección porque el tamaño de muestra es pequeño y por ende no aporta mucho al estudio, por esta razón la muestra baja de 19 a 18 universidades privadas.

En cambio, en las universidades del $\mathrm{CRUCH}$ existen dos universidades cuya dependencia es de Prorrectoría. Como esta instancia universitaria subroga directamente a la Rectoría, los dos casos de la Prorrectoría fueron asociados a la Rectoría, y por ello, aumentaron de 18 a 20 las unidades que dependen de la Rectoría.

En ambas situaciones, estas asociaciones se realizan porque existen casos con poca frecuencia. En concreto, ambas pruebas arrojaron un valor-p superior a 0,10; lo que significa que la relación entre el número de años de acreditación y la dependencia administrativa de la 
unidad encargada de la acreditación institucional no es estadísticamente significativa, por lo cual se confirma la hipótesis bajo estudio.

Tabla 7: Tabla de contingencia del número de universidades chilenas, por categoría de años de acreditación y dependencia, de la unidad encargada de la acreditación institucional al año 2015

\begin{tabular}{|c|c|c|c|c|c|c|}
\hline \multirow{2}{*}{$\begin{array}{l}\text { Unidades de las } \\
\text { cuales depende la } \\
\text { acreditación } \\
\text { institucional }\end{array}$} & \multicolumn{3}{|c|}{ CRUCH } & \multicolumn{3}{|c|}{ Privadas } \\
\hline & $\begin{array}{c}\text { Posee } 5 \text { a } 7 \\
\text { años de } \\
\text { acreditación }\end{array}$ & $\begin{array}{c}\text { Posee } 1 \text { a } 4 \\
\text { años de } \\
\text { acreditación }\end{array}$ & Total & $\begin{array}{c}\text { Posee } 5 \text { a } 7 \\
\text { años de } \\
\text { acreditación }\end{array}$ & $\begin{array}{l}\text { Posee } 1 \text { a } 4 \text { años } \\
\text { de acreditación }\end{array}$ & Total \\
\hline Rectoría & 10 & 10 & 20 & 4 & 8 & 12 \\
\hline Vicerrectoría & 4 & 1 & 5 & 3 & 3 & 6 \\
\hline Total & 14 & 11 & 25 & 7 & 11 & 18 \\
\hline
\end{tabular}

Fuente: Elaboración propia (2015)

De manera similar a la Tabla 7 , la Tabla 8 presenta la tabla de contingencia del número de universidades chilenas al 2015, por categoría y dependencia, de la unidad encargada de la acreditación institucional.

Para determinar si el número de áreas acreditadas está asociado con la dependencia administrativa de la unidad encargada de la acreditación institucional, se realizó también una prueba Chi-cuadrado de independencia y la Prueba exacta de Fisher. Al igual que la Tabla 7, para la realización de estas pruebas no se consideró el caso de la dirección de la universidad privada, por ser poco representativo, disminuyendo los casos de 19 a 18 universidades y la Prorrectoría también fue asociada a la Rectoría por presentar muy baja frecuencia. En concreto, se agruparon en una categoría las universidades con acreditaciones en 2 o 3 áreas y en otra categoría las que poseen más de 3 áreas, quedando una tabla de 2x2 como sigue:

Tabla 8. Tabla de contingencia del número de universidades chilenas, por categoría de áreas de acreditación y dependencia, de la unidad encargada de la acreditación institucional al año 2015

\begin{tabular}{|c|c|c|c|c|c|c|}
\hline \multirow{3}{*}{$\begin{array}{c}\text { Áreas de } \\
\text { acreditación } \\
\text { Institucional }\end{array}$} & \multicolumn{3}{|c|}{ CRUCH } & \multicolumn{3}{|c|}{ Privadas } \\
\hline & Depe & dencia & & Dep & dencia & \\
\hline & Rectoría & Vicerrectoría & Total & Rectoría & Vicerrectoría & Total \\
\hline 203 & 10 & 1 & 11 & 10 & 4 & 14 \\
\hline 405 & 10 & 4 & 14 & 2 & 2 & 3 \\
\hline Total & 20 & 5 & 25 & 12 & 6 & 18 \\
\hline
\end{tabular}

Fuente: Elaboración propia (2015)

En este caso, las pruebas de independencia Chi-cuadrado y de Fisher dieron como resultado un valor-p superior a 0,10. Por lo tanto, se concluye que la dependencia organizacional de la unidad encargada de la acreditación institucional es estadísticamente independiente del número de áreas acreditadas, lo cual confirma la hipótesis bajo estudio. 


\subsection{Análisis de correspondencias múltiples}

En esta sección se presentan los resultados de un análisis de correspondencias múltiples, el cual es una técnica descriptiva que se utiliza para representar gráficamente una tabla de contingencia para más de dos variables categóricas. El objetivo consiste en analizar las tres siguientes variables a la vez: Dependencia organizacional de la unidad encargada de la acreditación institucional, el número de años y áreas de acreditación obtenidos.

Las variables objeto de estudio y sus categorías, son las siguientes:

- Dependencia organizacional: Rectoría, Prorrectoría, Vicerrectoría.

- Años de acreditación: 1 a 3, 4 ó 5, 6 ó 7 años de acreditación institucional.

- Número de áreas acreditadas: 2, 3, 4 y 5 áreas acreditadas.

Tabla 9. Varianza explicada, por categoría, del análisis de correspondencias múltiples de las universidades chilenas al año 2015

\begin{tabular}{|c|c|c|c|c|}
\hline \multicolumn{5}{|c|}{ CRUCH } \\
\hline \multirow[b]{2}{*}{ Dimensión } & \multirow[b]{2}{*}{$\begin{array}{c}\text { Alfa de } \\
\text { Cronbach }\end{array}$} & \multicolumn{3}{|c|}{ Varianza explicada } \\
\hline & & $\begin{array}{c}\text { Total } \\
\text { (Autovalores) }\end{array}$ & Inercia & $\%$ de la varianza \\
\hline 1 & 0,777 & 2,076 & 0,692 & 69,186 \\
\hline 2 & 0,368 & 1,325 & 0,442 & 44,154 \\
\hline Total & & 3,400 & 1,133 & \\
\hline Media & $0,618^{a}$ & 1,700 & 0,567 & 56,670 \\
\hline
\end{tabular}

a. El Alfa de Cronbach Promedio está basado en los autovalores promedio. PRIVADAS

\begin{tabular}{|c|c|c|c|c|}
\hline \multirow[b]{2}{*}{ Dimensión } & \multirow[b]{2}{*}{$\begin{array}{c}\text { Alfa de } \\
\text { Cronbach }\end{array}$} & \multicolumn{3}{|c|}{ Varianza explicada } \\
\hline & & $\begin{array}{c}\text { Total } \\
\text { (Autovalores) }\end{array}$ & Inercia & $\%$ de la varianza \\
\hline 1 & 0,797 & 2,133 & 0,711 & 71,114 \\
\hline 2 & 0,676 & 1,821 & 0,607 & 60,705 \\
\hline Total & & 3,955 & 1,318 & \\
\hline Media & $0,741^{a}$ & 1,977 & 0,659 & 65,909 \\
\hline
\end{tabular}

a. El Alfa de Cronbach Promedio está basado en los autovalores promedio.

\begin{tabular}{|l|r|r|r|r|}
\hline \multicolumn{5}{|c|}{ COMPARATIVO CRUCH Y PRIVADAS } \\
\cline { 3 - 5 } & \multirow{2}{*}{$\begin{array}{c}\text { Alfa de } \\
\text { Cronbach }\end{array}$} & $\begin{array}{c}|c| \\
\text { Tarianza explicada } \\
\text { (Autovalores) }\end{array}$ & Inercia & $\%$ de la varianza \\
\hline 1 & 0,682 & 2,047 & 0,512 & 51,168 \\
\hline 2 & 0,419 & 1,458 & 0,365 & 36,458 \\
\hline Total & & 3,505 & 0,876 & 43,813 \\
\hline Media & $0,573 a$ & 1,753 & 0,438 & \\
\hline \multicolumn{4}{|r}{ a. La media de alfa de Cronbach se basa en la media de autovalor } \\
\hline
\end{tabular}

Fuente: Elaboración propia (2015)

Tal como se observa en la Tabla 9, en las universidades del $\mathrm{CRUCH}$, el porcentaje de la varianza explicada del estudio es superior al 50\%, específicamente el $56 \%$, y en el caso de las universidades privadas, es del $65 \%$, con lo cual el porcentaje restante queda 
explicado por otras variables no recogidas en el estudio. En cambio, al realizar un análisis comparativo entre universidades del $\mathrm{CRUCH}$ y privadas, el porcentaje de la varianza explicada del estudio baja a $43,81 \%$, lo cual se puede deber a la mayor diversidad de universidades en el análisis.

Figura 2. Diagrama conjunto de puntos de categorías de universidades del CRUCH

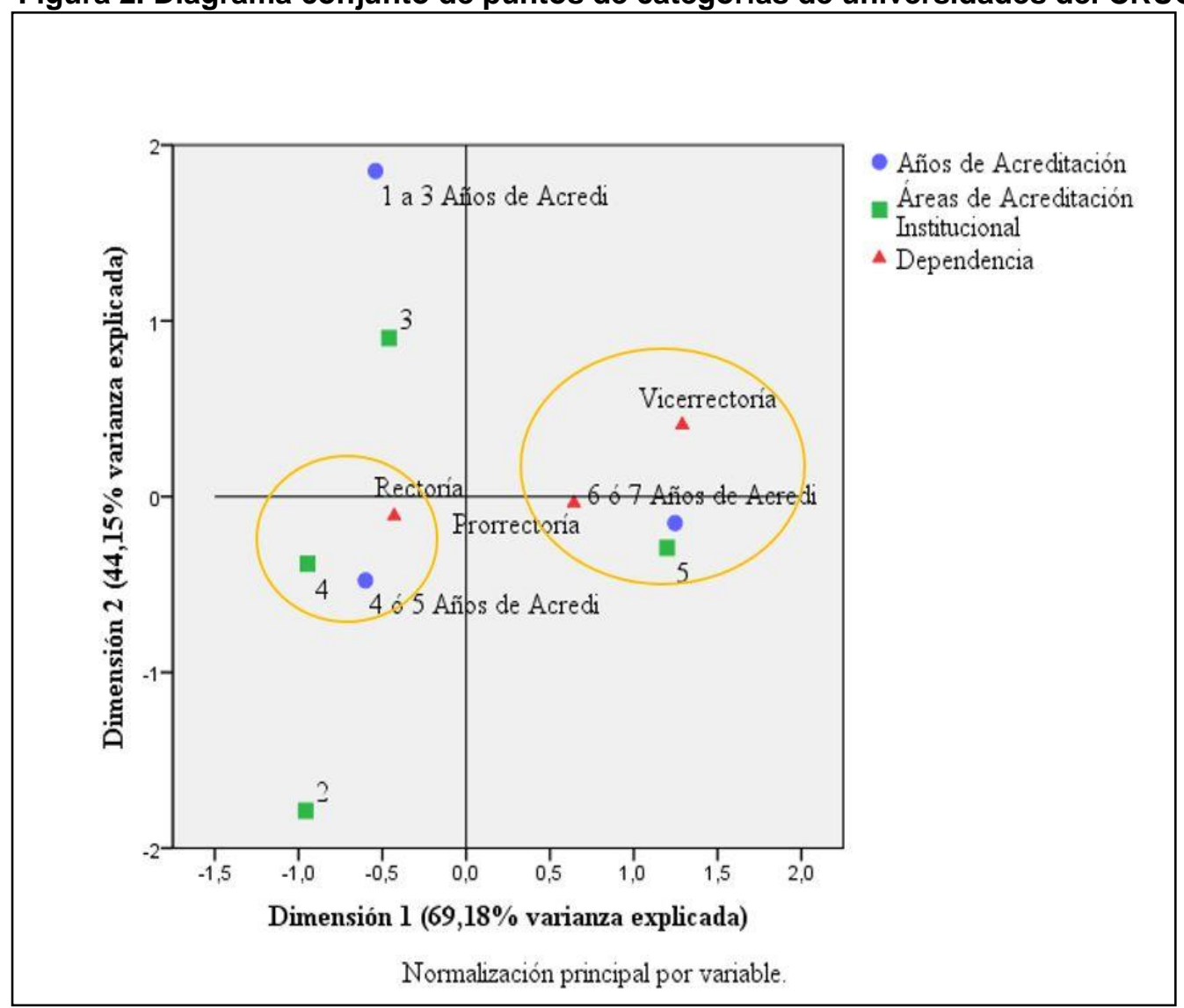

Fuente: Elaboración propia (2015)

Como se puede observar en la Figura 2, para las universidades del $\mathrm{CRUCH}$, la dimensión 1 presenta un mayor porcentaje de varianza explicada, 69,18\%; por ende, posee mayor capacidad explicativa del fenómeno analizado. De esta forma, se puede observar que las instituciones que dependen de Vicerrectoría se caracterizan principalmente por tener 6 ó 7 años de acreditación y 5 áreas acreditadas, aunque esta asociación no resulta ser tan significativa debido a que se encuentra distribuida en dos cuadrantes diferentes (I y IV), esto a diferencia de las instituciones que dependen de Rectoría, que se asocian más con alcanzar 4 ó 5 años de acreditación y 4 áreas, tal como se observa en el cuadrante III. En cambio, el cuadrante II representa a las instituciones con 1 a 3 años de acreditación. Lo mismo se 
puede señalar de las instituciones que poseen 2 ó 3 áreas de acreditación. Por ende, se puede concluir que, al considerar las tres variables analizadas de manera simultánea, existen indicios de asociación entre la dependencia organizacional, los años y las áreas de acreditación institucional.

Figura 3. Diagrama conjunto de puntos de categorías de universidades privadas

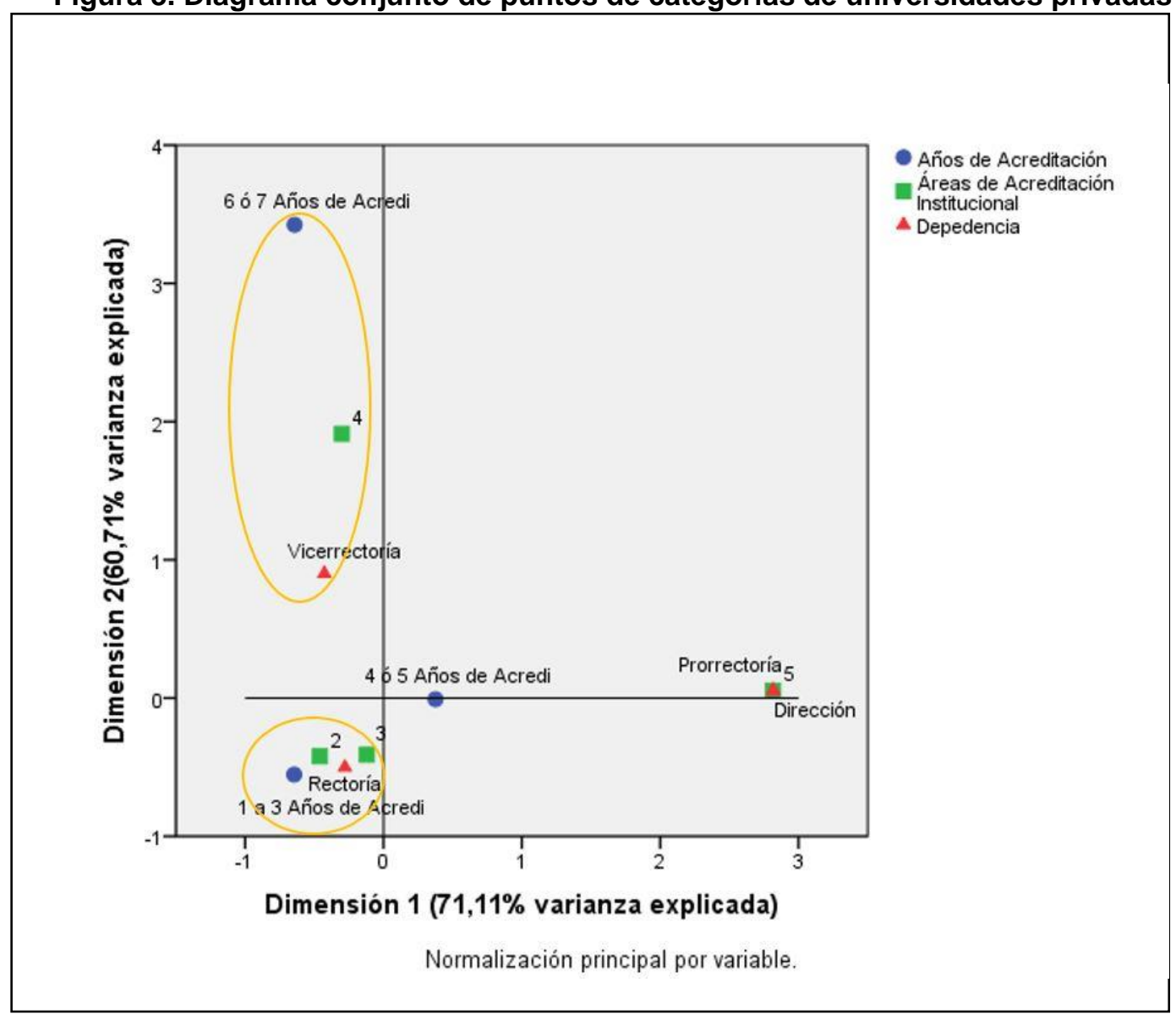

Fuente: Elaboración propia (2015)

De manera similar, en la Figura 3, para las universidades privadas, la dimensión 1 presenta un mayor porcentaje de varianza explicada, $71,11 \%$. De esta forma, se puede observar, en el cuadrante III, que las instituciones que dependen de Rectoría, se caracterizan por tener 1 a 3 años de acreditación y 2 o 3 áreas acreditadas. En cambio, las instituciones con 4, $5 \circ 6$ años de acreditación no presentan asociación significativa con algún grupo de dependencia. Lo mismo se puede señalar de las instituciones que poseen 4 o 5 áreas de acreditación. Por ende, se puede concluir que, en conjunto, es decir, considerando las tres variables analizadas simultáneamente, existen indicios de asociación 
solo entre la dependencia organizacional, cuya categoría es la rectoría, con 1 a 3 años y 2 y 3 áreas de acreditación institucional en el caso de las universidades privadas.

Figura 4. Diagrama conjunto de puntos de categorías de universidades $\mathrm{CRUCH}$ y privadas al año 2015

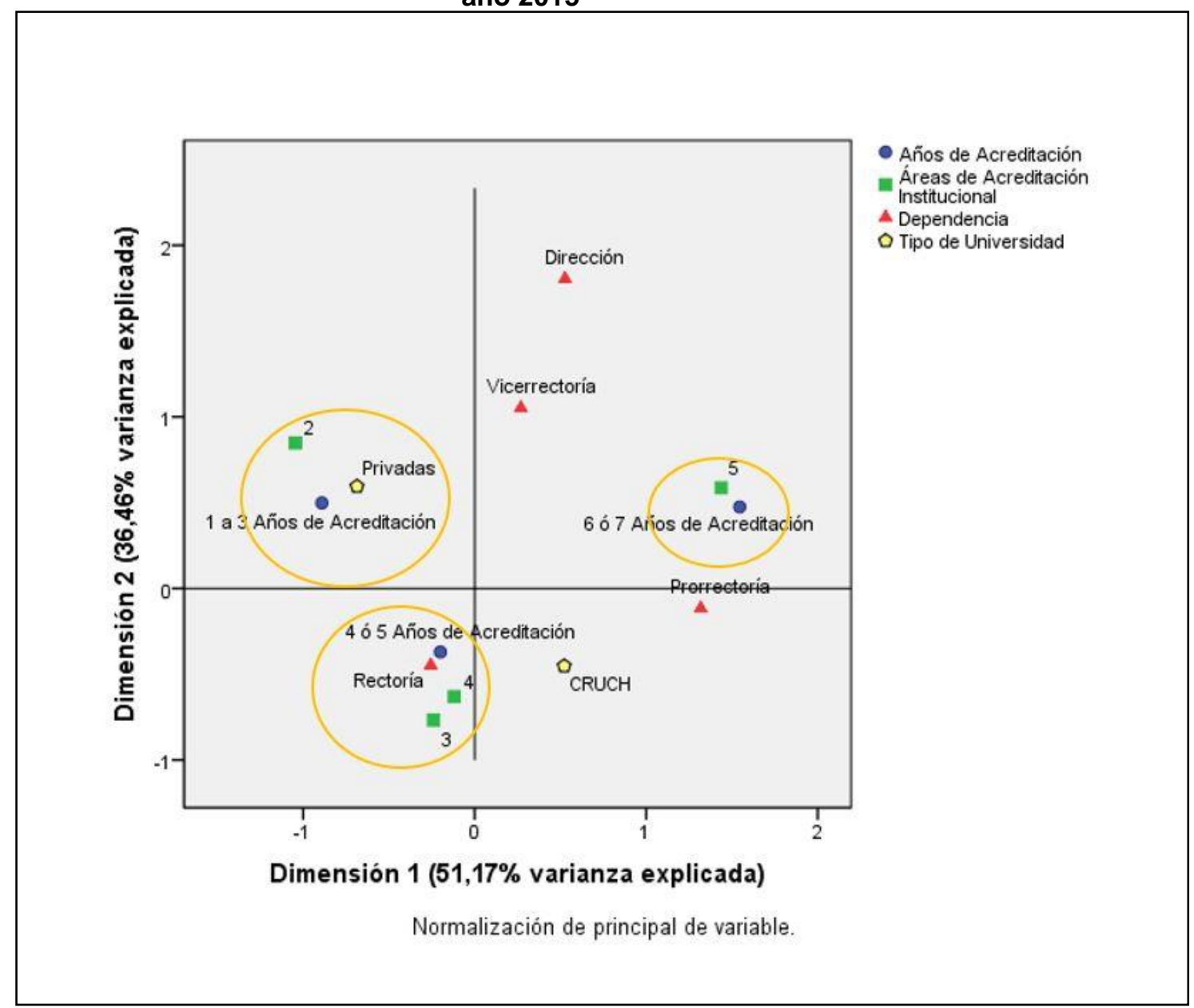

Fuente: Elaboración propia (2015)

La Figura 4 representa el diagrama conjunto de puntos de categorías comparativo entre universidades $\mathrm{CRUCH}$ y universidades privadas. Tal como se puede apreciar, la dimensión 1 presenta un porcentaje de varianza explicada de 51,17\%, donde la variable que se representa con mayor fuerza en esta dimensión son los años de acreditación, a diferencia de la dimensión 2, que se encuentra más asociada a la dependencia organizacional. En cambio, tanto el tipo de universidad ( $\mathrm{CRUCH}$ y privadas) como las áreas de acreditación están en un punto intermedio entre ambas dimensiones, según el resultado de las medidas discriminantes. 
En concreto, como se puede observar en el cuadrante III, existe asociación entre las universidades cuya dependencia organizacional de la acreditación institucional es una Rectoría y presenta 4 o 5 años de acreditación y 3 o 4 áreas. Sin embargo, que sean del $\mathrm{CRUCH}$ o Privada no es una variable influyente en esta asociación. Además, tal como se visualiza, que una universidad sea del $\mathrm{CRUCH}$ no se asocia a los años y áreas de acreditación que obtenga (cuadrante IV). En cambio, se observa en el cuadrante II, que sí existe una asociación entre universidades privadas que obtienen 2 áreas y de 1 a 3 años de acreditación. Al igual que en el cuadrante I, se aprecia una asociación entre aquellas universidades que obtienen 5 áreas y 6 o 7 años de acreditación. Esta última asociación nos lleva a concluir que la mayor acreditación, en años y áreas, o lo que se puede interpretar como mayor calidad, no está asociada a un tipo de universidad, es decir, la naturaleza jurídica de una institución, sea el $\mathrm{CRUCH}$ o privada, no se asocia necesariamente a una mejor calidad.

Tabla 10. Resultado de las medidas de discriminación de las universidades chilenas por categoría al año 2015

\begin{tabular}{|c|c|c|c|c|c|c|c|c|c|}
\hline \multirow{3}{*}{ Variables } & \multicolumn{3}{|c|}{ CRUCH } & \multicolumn{3}{|c|}{ PRIVADAS } & \multicolumn{3}{|c|}{ CRUCH Y PRIVADAS } \\
\hline & \multicolumn{2}{|c|}{ Dimensión } & \multirow{2}{*}{ Media } & \multicolumn{2}{|c|}{ Dimensión } & \multirow{2}{*}{ Media } & \multicolumn{2}{|c|}{ Dimensión } & \multirow{2}{*}{ Media } \\
\hline & 1 & 2 & & 1 & 2 & & 1 & 2 & \\
\hline $\begin{array}{l}\text { Áreas de Acreditación } \\
\text { Institucional }\end{array}$ & 0,846 & 0,608 & 0,727 & 0,953 & 0,705 & 0,829 & 0,811 & 0,525 & 0,668 \\
\hline Años de Acreditación & 0,731 & 0,675 & 0,703 & 0,243 & 0,714 & 0,478 & 0,692 & 0,181 & 0,436 \\
\hline Dependencia & 0,498 & 0,042 & 0,270 & 0,938 & 0,402 & 0,670 & 0,186 & 0,484 & 0,335 \\
\hline Tipo de Universidad & & & & & & & 0,358 & 0,269 & 0,314 \\
\hline Total activo & 2,076 & 1,325 & 1,700 & 2,133 & 1,821 & 1,977 & 2,047 & 1,458 & 1,753 \\
\hline$\%$ de la varianza & 69,186 & 44,154 & 56,670 & 71,114 & 60,705 & 65,909 & 51,168 & 36,458 & 43,813 \\
\hline
\end{tabular}

Fuente: Elaboración propia (2015)

La Tabla 10 refleja las medidas de discriminación evidenciando el porcentaje de varianza explicada del estudio, y el resultado de cada dimensión de forma específica.

Adicionalmente al resultado anterior y con la finalidad de profundizar en el análisis de los datos, se determinó el odds ratio de los años y áreas de acreditación, por categoría de universidad, a través de las Tabla 11 y 12 respectivamente.

El odds ratio denotado por OR, que también se llama razón del producto cruzado, se utiliza para conocer la posibilidad de ocurrencia de un evento en relación con otro. 
Tabla 11: ODDS RATIO (OR) de los Años de acreditación de las universidades chilenas por categoría al año 2015

\begin{tabular}{|l|r|r|}
\hline \multirow{2}{*}{ Categoría } & \multicolumn{3}{|c|}{$\begin{array}{c}\text { Años de acreditación } \\
\text { Institucional }\end{array}$} \\
\cline { 2 - 3 } & $\mathbf{5}$ a 7 & \multicolumn{1}{|c|}{$\mathbf{1}$ a 4 } \\
\hline Universidades del CRUCH & 14 & 11 \\
\hline Universidades Privadas & 8 & 11 \\
\hline Total & $\mathbf{2 2}$ & $\mathbf{2 2}$ \\
\hline
\end{tabular}

Fuente: Elaboración propia (2015), a partir de www.cnachile.cl

De la Tabla 11, se tiene que el odds ratio es igual a 1,75, lo que significa que la acreditación institucional de 5 a 7 años es 1,75 veces mayor en las universidades del $\mathrm{CRUCH}$ en comparación con las universidades Privadas. Además, al aplicar las pruebas de independencia Chi-cuadrado y la prueba exacta de Fisher, se concluye que la asociación entre el tipo de universidad y los años de acreditación institucional no es estadísticamente significativa (valor-p > 0,10 en ambas pruebas). De hecho, según Domínguez - Lara (2017) la fuerza de la asociación se considera pequeña.

Tabla 12: ODDS RATIO (OR) de las áreas de acreditación de las universidades chilenas por categoría al año 2015

\begin{tabular}{|l|r|r|}
\hline \multirow{2}{*}{ Categoría } & \multicolumn{3}{|c|}{$\begin{array}{c}\text { Áreas de acreditación } \\
\text { Institucional }\end{array}$} \\
\cline { 2 - 4 } & $\mathbf{5}$ & $\mathbf{2}$ \\
\hline Universidades del CRUCH & 9 & 16 \\
\hline Universidades Privadas & 2 & 17 \\
\hline Total & $\mathbf{1 1}$ & $\mathbf{3 3}$ \\
\hline
\end{tabular}

Fuente: Elaboración propia (2015), a partir de www.cnachile.cl

De la Tabla 12, se tiene que el odds ratio es igual a 4,78 , lo que significa que la acreditación de cinco áreas es 4,78 veces mayor en las universidades del CRUCH en comparación con las universidades privadas. Al aplicar las pruebas de independencia Chicuadrado y la prueba exacta de Fisher, se concluye que la asociación entre el tipo de universidad y la cantidad de áreas acreditadas es estadísticamente significativa (valor-p aproximadamente de 0,05 en ambas pruebas). Y según Domínguez y Lara (2017), la fuerza de la asociación se considera de moderada a grande. 


\section{Conclusiones}

Los procesos de acreditación han evolucionado a través del tiempo, y es importante, en esta nueva mirada, lo cuantitativo, el análisis crítico, la deducción en torno a los avances y la evidencia de lo presentado.

Lo anterior está en línea con la reforma educacional que plantea que la acreditación será un proceso integral, que contemplará la acreditación institucional y la acreditación de carreras. Este aspecto ya ha sido abordado en otras latitudes, tal como el Consejo Nacional de Acreditación de Colombia donde se plantea que:

La acreditación institucional y la acreditación de programas académicos son complementarios. $\mathrm{Y}$ esa complementariedad consiste en que la acreditación institucional se orienta hacia la institución como un todo, mientras que la acreditación de programas considera a estos últimos como partes integrales de ese todo. (Consejo Nacional de Acreditación, 2014, p. 14)

En concreto, el presente artículo tuvo como objetivo analizar la dependencia organizacional de la unidad encargada del proceso de acreditación institucional. Para ello, se realizó un análisis cuantitativo y descriptivo de las universidades chilenas acreditadas, del Consejo de Rectores y de las Universidades Privadas al año 2015. Lo anterior, a partir de información obtenida de la Comisión Nacional de Acreditación, de las páginas web e información telefónica de las universidades. Los análisis estadísticos incluyeron estadísticas descriptivas, tablas de contingencias y análisis de correspondencias múltiples.

A través de un análisis de correspondencias múltiples, los resultados del estudio permiten concluir que no necesariamente la dependencia organizacional de la acreditación institucional explica los años y áreas de acreditación. Lo anterior, porque se descubrió que solo existen indicios de asociación entre la dependencia organizacional, los años y las áreas de acreditación institucional obtenidos por las universidades del Consejo de Rectores de Universidades Chilenas, lo cual en parte se puede deber a la cercanía jerárquica con la toma de decisiones, y por ende, a la posibilidad que tienen las unidades de influir en las áreas que se consideran en los procesos de acreditación de las instituciones.

En particular, los resultados del estudio evidencian que en las universidades del $\mathrm{CRUCH}$, el $72 \%$ de las unidades encargadas de la acreditación institucional dependen de rectoría, a diferencia de las universidades privadas, que representa un $58 \%$. Por otra parte, con el análisis de correspondencias múltiples, se obtuvo una varianza explicada para las 
universidades del $\mathrm{CRUCH}$ de un $56 \%$, de un $65 \%$ para las universidades privadas y de un $43 \%$ cuando se realiza el análisis comparativo entre ambos tipos de universidades. Este resultado se puede deber a la mayor diversidad que se genera al analizar ambos tipos de universidades de manera simultánea.

A la vez, cuando se realiza un análisis de correspondencias múltiples, por tipo de universidad, en el caso del $\mathrm{CRUCH}$, se descubre que existen indicios de asociación entre la dependencia organizacional, los años y las áreas de acreditación institucional, a diferencia de las universidades privadas en donde se evidencia, principalmente, la asociación a través de la categoría rectoría con 1 a 3 años y 2 o 3 áreas de acreditación. En cambio, cuando se realiza el análisis comparativo, se observa una asociación entre las universidades cuya unidad encargada del proceso de acreditación, dependen de una rectoría, poseen 4 ó 5 años y 3 ó 4 áreas de acreditación. Al igual que se descubre que existe una asociación entre las universidades que obtienen 5 áreas y 6 o 7 años, sin ser relevante el tipo de universidad. Esta última asociación nos lleva a concluir que la mayor acreditación, en años y áreas, o lo que se puede interpretar como mayor calidad, no está asociada a un tipo de universidad; es decir, la naturaleza jurídica de una institución, sea del CRUCH o privada, no se asocia necesariamente con una mejor calidad, a diferencia de la asociación entre las universidades privadas que obtienen 2 áreas y de 1 a 3 años de acreditación.

El análisis comparativo permite apreciar las asociaciones que se producen en las universidades chilenas, siendo consistentes con los resultados previos. Finalmente, de acuerdo con los odds ratio la acreditación de 5 áreas es 4,78 veces mayor en universidades del $\mathrm{CRUCH}$ en relación con universidades privadas. En definitiva, los resultados permiten confirmar la hipótesis bajo estudio, esta es, que no existe asociación altamente significativa entre la dependencia organizacional y los resultados obtenidos en el proceso de acreditación. Lo mencionado supra evidencia la necesidad de continuar profundizando el análisis de la dependencia de la unidad encargada de la acreditación, en las instituciones de educación superior, por su impacto en los procesos de acreditación.

Por lo tanto, los resultados que se obtengan en el proceso de acreditación deben considerar la dependencia organizacional de la unidad encargada de la acreditación en conjunto con otros elementos que condicionan los resultados obtenidos.

Sin embargo, se debe considerar que los resultados pueden estar influenciados por la mayor representación y dispersión en los años y áreas de acreditación que poseen las unidades que dependen de Rectoría con respecto a aquellas que dependen de Vicerrectoría, 
y en menor medida en Prorrectoría, cuya representatividad es menor y sus resultados son menos dispersos. Al igual que por otras variables no recogidas en el estudio y por esta situación, se plantea, en el próximo apartado, como una limitación del estudio.

Finalmente, una futura línea de investigación consiste en realizar un estudio comparativo entre países.

\section{Limitaciones del estudio}

Una de las limitaciones del estudio es el escaso número de datos que presentan algunas categorías de la variable dependencia organizacional, como la categoría asociada a una dirección o prorrectoría, lo que reduce la muestra inicial por su escasa representatividad. Lo anterior, junto a otras variables que puedan medir el resultado de los procesos de acreditación 0 las consecuencias de obtener la acreditación institucional en las universidades, tales como el prestigio, el aumento de matrícula, entre otros.

\section{Referencias}

Acosta, Abril. (2015). La FIMPES y la mejora de la calidad de instituciones privadas: Un estudio acerca del concepto de calidad y de los procesos de acreditación en tres universidades particulares. Revista de la Educación Superior, 44(175), 169-175.

Aguilar, María. (2016). La visibilidad del conocimiento y los retos de la acreditación institucional. Diversitas: Perspectivas en Psicología, 12(1), 9-10. Recuperado de http://www.scielo.org.co/scielo.php?script=sci arttext\&pid=S1794$99982016000100001 \& \operatorname{lng}=e s \& n r m=i s \& t \operatorname{lng}=e n$

Anzola, Germán. (2013). La investigación en el proceso de acreditación institucional en la U.D.C.A. Revista U.D.C.A Actualidad \& Divulgación Científica, 16(1), 1-2. Recuperado de $\quad$ http://www.scielo.org.co/scielo.php?script=sci arttext\&pid=S0123$\underline{42262013000100001}$

Araujo, Sonia. (2014). La evaluación y la Universidad en Argentina: políticas, enfoques y prácticas. Revista de la Educación Superior, 43(172), 57-77. Recuperado de http://www.redalyc.org/pdf/604/60432737009.pdf

Barra, Ana y Gómez, Nelly. (2014). Relación entre los insumos del plan estratégico y los resultados para la acreditación: Caso aplicado a universidades chilenas. Actualidades Investigativas en Educación, 14(3), 382-402. Recuperado de https://revistas.ucr.ac.cr/index.php/aie/article/view/16128/18109

Barra, Ana y Gómez, Nelly. (2015). Análisis comparativo entre universidades estatales y no estatales de Chile respecto de su dirección estratégica. Actualidades Investigativas en Educación, 15(2), 131-151. Recuperado de https://revistas.ucr.ac.cr/index.php/aie/article/view/18949 
Borroto, Eugenio y Salas, Ramón. (2004). Acreditación y evaluación universitarias. Escuela Nacional de Salud Pública, 18(3), 1-12. Recuperado de http://scielo.sld.cu/scielo.php?script=sci arttext\&pid=S0864-21412004000300001

Cancino, Víctor y Schmal, Rodolfo. (2014). Sistema de acreditación universitaria en Chile: ¿Cuánto hemos avanzado? Estudios Pedagógicos, 40(1), 41-60. Recuperado de http://www.scielo.cl/pdf/estped/v40n1/art03.pdf

Comisión Nacional de Acreditación de Chile, (CNA-Chile). (2013). Aprueba reglamento sobre áreas de acreditación acorde al artículo $17^{\circ}$ de la Ley 20.129. Resolución Exenta DJ $N^{\circ} 01$. Recuperado de https://www.cnachile.cl/Documentos\%20de\%20Paginas/RES-DJ01.pdf

Comisión Nacional de Acreditación de Chile (CNA-Chile). (2014). Aprueba reglamento que fija el procedimiento para el desarrollo de los procesos de acreditación institucional. Resolución Exenta DJ N009-4. Recuperado de https://www.cnachile.cl/Documentos\%20de\%20Paginas/Reglamento Al 24102014.pdf

Comisión Nacional de Acreditación de Chile, (CNA-Chile). (2015). Acreditación Institucional. Santiago de Chile: Comisión Nacional de Acreditación de Chile. Recuperado de https://www.cnachile.cl/Paginas/preguntasfrecuentes.aspx

Consejo Nacional de Acreditación (CNA) de Colombia. (2014). Sistema Nacional de Acreditación. Lineamientos para la Acreditación Institucional. Bogotá: Consejo Nacional de Acreditación. Recuperado de https://www.cna.gov.co/1741/articles186359 Lin Ins 2014.pdf

Cuevas, Yazmín. (2011). Organismos y procesos de certificación de calidad de la educación superior privada en México. Calidad En La Educación, (35), 231-254.

Domínguez-Lara, Sergio. (2017). El odds ratio y su interpretación como magnitud del efecto en investigación. Educación Médica. Recuperado de https://doi.org/10.1016/j.edumed.2017.01.008

Espinoza, Oscar y González, Luis. (2012). Estado actual del sistema de aseguramiento de la calidad y el régimen de acreditación en la educación superior en Chile. Revista de la Educación Superior, 41(162), 87-109. Recuperado de http://www.scielo.org.mx/scielo.php?pid=S0185$27602012000200005 \&$ script=sci abstract

Flórez, Ordoñez y Yudy, Natalia. (2016). Acreditación institucional multicampus. Iteckne, 13(1), $6 . \quad$ Recuperado de http://revistas.ustabuca.edu.co/index.php/ITECKNE/article/view/1376/1113

Gairín, Joaquín y Martín, Mario. (2011). La acreditación en las instituciones de educación superior. Santiago, Chile: Comisión Nacional de Acreditación CNA-Chile. Fundación Creando Futuro.

Lemaitre, María, Maturana, Mario, Zenteno, Elisa y Alvarado, Andrea. (2012). Cambios en la gestión institucional en universidades, a partir de la implementación del sistema 
nacional de aseguramiento de la calidad: la experiencia chilena. Calidad en la Educación, (36), 21-52. Recuperado de http://www.scielo.cl/scielo.php?script=sci arttext\&pid=S0718-

$45652012000100001 \& \operatorname{lng}=e s \& n r m=i s o \& t \operatorname{lng}=e s$

LLanio, Giraldo, Dopico, lleana y Suros, Esther. (2011). La evaluación del impacto de los procesos de acreditación. Variables e indicadores. Pedagogía Universitaria, 16(1), 1 12. Recuperado de http://cvi.mes.edu.cu/peduniv/index.php/peduniv/article/view/58

Martínez, Jorge, Tobon, Sergio y Romero, Aarón. (2017). Problemáticas relacionadas con la acreditación de la calidad de la educación superior en América Latina. Innovación Educativa, 17(73), 79-96. Recuperado de http://www.scielo.org.mx/scielo.php?pid=S166526732017000100079\&script=sci abstract

Ministerio de Educación, Chile. (2006). Ley de Aseguramiento de la Calidad №20.129. Sistema Nacional de Aseguramiento de la Calidad de la Educación Superior. Santiago de Chile: Biblioteca del Congreso Nacional de Chile. Recuperado de https://www.cnachile.cl/SiteAssets/Paginas/Ley\%2020129/LEY-20129 17-NOV$2006 \% 20$ ASEGURAMIENTO\%20DE\%20LA\%20CALIDAD\%20(002).pdf

Ministerio de Educación, Chile. (2005). DFL 1: Fija texto refundido, coordinado y sistematizado de la Ley № 18.962, orgánica constitucional de enseñanza (última modificación: 12-sep-2009 ley 20370). Santiago de Chile: Ministerio de Educación. Biblioteca del Congreso Nacional de Chile. Recuperado de https://www.leychile.cl/Navegar?idNorma=247551\&idVersion

Ministerio de Educación, Chile. (2013). Decreto 97: reglamenta el programa de becas de educación superior (última modificación: 02-junio-2017 decreto 253). Santiago de Chile: Ministerio de Educación. Biblioteca del Congreso Nacional de Chile. Recuperado de https://www.leychile.cl/Navegar?idNorma=1055001

Minte, Andrea y López, Daniel. (2009). Modelo de respuesta a la acreditación institucional. La experiencia de la Universidad de los Lagos. Calidad en la Educación, (31), 145-165. Recuperado de https://www.cned.cl/file/1278/download?token=40XdDKet

Mollis, Marcela. (2007). La educación superior en Argentina: balance de una década. Revista de la Educación Superior, 36(142), 69-85. Recuperado de http://www.scielo.org.mx/scielo.php?script=sci arttext\&pid=S018527602007000200004

Mollis, Marcela. (2014). Administrar la crisis de la educación pública y evaluar la calidad universitaria en América Latina: dos caras de la misma reforma educativa. Revista de la Educación Superior, 43(169), 25-45. Recuperado de http://www.sciencedirect.com/science/article/pii/S0185276015000047

Organización para la Cooperación y el Desarrollo Económicos - OCDE y Banco Mundial. (2010). La Región del Bío-Bío, Chile : Informe de la OCDE - Banco Mundial sobre la contribución de la Educación Superior en el Desarrollo Regional. Concepción, Chile: OECD, The World Bank. 
Rama, Claudio. (2009). El nacimiento de la acreditación internacional. Avaliação, Campinas; Sorocaba, 14(2), 267-290. Recuperado de http://www.scielo.br/pdf/aval/v14n2/a04v14n2

Ramírez, Patricio y Alfaro, Jorge. (2013). Evaluación de la eficiencia de las universidades pertenecientes al Consejo de Rectores de las Universidades Chilenas: resultados de un análisis envolvente de datos. Formación Universitaria, 6(3), 31-38. Recuperado de http://www.scielo.cl/scielo.php?script=sci arttext\&pid=S0718-50062013000300005

Rojas Ríos, María y López Stefoni, Daniel. (2016). La acreditación de la gestión institucional en universidades chilenas. Revista Electrónica de Investigación Educativa, 18(2), 180190. Recuperado de https://redie.uabc.mx/redie/article/view/856

Rodríguez, Emilio, Fleet, Nicolás y Delgado, Milagros. (2010). Capacidad predictiva de la evaluación de los pares y focos del modelo de acreditación institucional en Chile. Revista da Avaliação da Educação Superior (Campinas), 15(1), 121-141. Recuperado de $\quad$ http://www.scielo.br/scielo.php?script=sci arttext\&pid=S1414$\underline{40772010000100007 \& \operatorname{lng}=e n \& n r m=i s o \& t \mid n g=e s}$

Rodríguez, Emilio, Fleet, Nicolás, Pedraja, Liliana y Rodríguez, Juan. (2012). Efecto de la calidad de la información sobre la acreditación institucional: un estudio exploratorio en universidades chilenas. Ingeniare. Revista Chilena de Ingeniería, 20(3), 368-375. Recuperado de http://www.scielo.cl/scielo.php?script=sci arttext\&pid=S0718$\underline{33052012000300011}$

Rodríguez, Emilio, Pedraja, Liliana, Araneda, Carmen, González, María y Rodríguez, Juan. (2011). El impacto del sistema de aseguramiento de la calidad en el servicio entregado por las universidades privadas en Chile. Ingeniare. Revista Chilena de Ingeniería, 19(3), 409-419. Recuperado de http://www.scielo.cl/scielo.php?script=sci arttext\&pid=S0718-33052011000300010

Tiscornia, Luis. (2009). El sistema de acreditación de las universidades nacionales a través de la CONEAU frente a la autonomía universitaria. Fundamento en Humanidades, 2(20), 45-54. Recuperado de http://fundamentos.unsl.edu.ar/pdf/articulo-20-45.pdf

Torres, Emilio. (2012). Acreditación institucional y la mirada de los actores. Un estudio cualitativo en universidades privadas de Santiago. Estudios Pedagógicos, 38(2), 221242. Recuperado de http://www.scielo.cl/scielo.php?script=sci arttext\&pid=S0718$\underline{07052012000200014}$

Tünnermann, Carlos. (2008). La calidad de la educación superior y su acreditación: la experiencia centroamericana. Avaliação, Campinas; Sorocaba, 13(2), 313-336. Recuperado de http://www.scielo.br/scielo.php?script=sci arttext\&pid=S141440772008000200005\&lng=en\&nrm=iso\&tlng=es

Velásquez, Jesús, Terrazas, Rosario y Ruiz, Luz. (2014). El sistema de gestión de calidad bajo las normas ISO 9001:2008 como elemento articulador de los lineamientos de la evaluación y acreditación de programas educativos de ciencias sociales y administrativa de la Universidad Estatal de Sonora. Global Conference on Business 
and Finance Proceedings, 9(1), 1213-1226. Recuperado de http://www.theibfr.com/ARCHIVE/ISSN-1941-9589-V9-N1-2014.pdf

Vélez, Julián. (2015). Más allá de la acreditación. CES Odontología, 28(1), 7-9. Recuperado de http://revistas.ces.edu.co/index.php/odontologia/issue/view/219

Venables, Juan y Van Gastel, Jilles. (2014). Radiografía de los modelos de acreditación: organización, procesos y prácticas. El caso de las Universidades Austral de Chile, de la Frontera y de los Lagos. Calidad en la Educación, (41), 51-81. Recuperado de http://www.scielo.cl/pdf/caledu/n41/art03.pdf

Vera, María y De Sierra, María. (2012). Tendencias y retos de dos universidades públicas latinoamericanas: (UNAM y UNC) ante las nuevas políticas públicas para la educación superior. Revista da PUCRS, 35(2), 241-252. Recuperado de http://revistaseletronicas.pucrs.br/ojs/index.php/faced/article/view/11638

Zapata, Gonzalo y Tejeda, Ivo. (2009). Impactos del aseguramiento de la calidad y acreditación de la educación superior. Consideraciones y proposiciones. Calidad en la Educación,

(31), 191-209.

https://dialnet.unirioja.es/servlet/articulo?codigo=3214471

Recuperado

de 